Robin Attfield and Andrew Belsey, eds, Philosophy and the Natural Environment Royal Institute of Philosophy Supplement: 36

Cambridge: Cambridge University Press, 1994. Pages 13-30

Conference address: Royal Institute of Philosophy Annual Conference University of Wales, Cardiff, 1993.

\title{
Value in Nature and the Nature of Value
}

\author{
HOLMES ROLSTON I I I
}

I offer myself as a nature guide, exploring for values. Many before us have got lost and we must look the world over. The unexamined life is not worth living; life in an unexamined world is not worthy living either. We miss too much of value.

\section{Valuable Humans}

Let us start from well-mapped ground: humans are able to value. Descartes's cogito is as well an indubitable valeo. I cannot doubt that I value. Humans are able to value nature instrumentally, to value their own experiential states both intrinsically and instrumentally. Objective natural things and events may contribute to these subjective interest satisfactions, a tree supplies firewood, a sunny day makes a picnic possible.

Taking the first step on our journey into non-human nature, some travellers notice that we must take along this indubitable valuing self; afterwards, along the way, finding these selves always present, they deny any value outside our own minds. Wilhelm Windelband insists: 'Value ... is never found in the object itself as a property. It consists in a relation to an appreciating mind .... Take away will and feeling and there is no such thing as value' (Windelband, 1921, p. 215). Bryan Norton concludes: 'Moralists among environmental ethicists have erred in looking for a value in living things that is independent of human Valuing. They have therefore forgotten a most elementary point about valuing anything. Valuing always occurs from the viewpoint of a conscious valuer .... Only the humans are valuing agents' (Norton, 1991, p. 251).

Taking an interest in an object gives humans a value-ability. Additionally to valuing nature instrumentally, humans can sometimes value nature intrinsically. When we value a giant sequoia tree, our valuing stops in the tree itself, without further contributory reference. What then is going on? Philosophical travellers, after taking a look at the tree, will want to take a look at their language. 'Intrinsic' means without instrumental reference, but that 


\section{Holmes Rolston III}

leaves unsettled whether the value is located in the tree independently, autonomously intrinsic, or placed on the tree upon our arrival. We cannot just take it as elementary that there is no such thing as non-human value. Is this intrinsic value discovered or conferred? There is excitement in the beholder; but what is valued is what is beheld.

If the value-ability of humans is the source of this valued excitement, then value is anthropogenic even though it is not anthropocentric (Callicott, 1984; 1986). Tourists in Yosemite do not value the sequoias as timber but as natural classics, for their age, strength, size, beauty, resilience and majesty. This viewing constitutes the trees' value, which is not present independent of the human valuing. Value thus requires subjectivity to coagulate it in the world. But the value so coagulated, it will be claimed, is placed objectively on the tree. Such value is not self-regarding, or even human-regarding, merely, though it is human-generated. It is not centred on human well-being. That ' $n$ is valuable' does mean that a human, $\mathrm{H}$, takes an interest in $n$, a natural object, but it need not mean ' $n$ satisfies $H$ 's desire', since $H$ may take an interest in the trees for what they are in themselves, and not merely to satisfy $H$ 's desires. Meanwhile, there is no value until consciousness comes on scene.

Visiting the Grand Canyon, we intrinsically value the rock strata with their colour bands. Visiting Kentucky, we value Mammoth Cave, with its stalactites. Taking any interest whatever constitutes value ipso facto. An otherwise valueless object can thus come to have intrinsic value. As travellers we will wonder what was here before, what will remain after. The obvious answer is that there will be whatever properties these trees, canyons, and caves have. Even Descartes found himself unable to doubt the existence of external nature, and no philosopher who doubts that the world exists bothers to take a trip through it.

What account do we give when, excited by a sense of deep time at the Grand Canyon, we realize that humans have rarely been there? At that point, we may wish to give a dispositional twist to value. To say that $n$ is valuable means that $n$ is able to be valued, if and when human valuers, $H$ 's, come along, but $n$ has these properties whether or not humans arrive. Faced with trilobite fossils, we conclude that the trilobites were potentially intrinsically valuable. By this account there is no actual value ownership autonomous to the valued and valuable trees, canyons, trilobites; there is a value ignition when humans arrive. Intrinsic value in the realized sense emerges relationally with the appearance of the subject-generator.

Despite the language of value conferral, if we try to take the 


\section{Value in Nature and the Nature of Value}

term intrinsic seriously, this cannot refer to anything the object gains, to something within ('intra') the present tree or the past trilobite, for the human subject does not really place anything on or in the natural object. We have only a 'truncated sense' of intrinsic (Callicott, 1986, p. 143). The attributes under consideration are objectively there before humans come, but the attribution of value is subjective. The object causally affects the subject, who is excited by the incoming data and translates this as value, after which the object, the tree, appears as having value, rather like it appears to have green colour. But nothing is really added intrinsically; everything in the object remains what it was before. Despite the language that humans are the source of value which they locate in the natural object, no value is really located there at all.

The term intrinsic, even when truncated, is misleading. What is meant is better specified by the term extrinsic, the ex indicating the external, anthropogenic ignition of the value, which is not in, intrinsic, internal to the nonsentient organism, even though this value, once generated, is apparently conferred on the organism. In the $H$ - $n$ encounter, value is conferred by $H$ on $n$, and that is really an extrinsic value for $n$, since it comes to $n$ from $H$, and likewise it is an extrinsic value for $H$, since it is conferred from $H$ to $n$, Neither $H$ nor $n$, standing alone, have such value.

We humans carry the lamp that lights up value, although we require the fuel that nature provides. Actual value is an event in our consciousness, though natural items while still in the dark of value have potential intrinsic value. Man is the measure of things, said Protagoras. Humans are the measurers, the valuers of things, even when we measure what they are in themselves.

\section{Valuable Animals}

A mother free-tail bat, a mammal like ourselves, can, using sonar, wend her way out of Bracken Cave, in Texas, in total darkness, catch 500-1000 insects each hour on the wing, and return to find and nurse her own young. That gives evidence of bat-valuing; she values the insects and the pup. Now, it seems absurd to say that there are no valuers until humans arrive. Animals do not make humans the measure of things at all. There is no better evidence of non-human values and valuers than spontaneous wildlife, born free and on its own. Animals hunt and howl, find shelter, seek out their habitats and mates, care for their young, flee from threats, grow hungry, thirsty, hot, tired, excited, sleepy. They suffer injury and lick their wounds. Here we are quite convinced that value is non-anthropogenic, to say nothing of anthropocentric. 


\section{Holmes Rolston III}

These wild animals defend their own lives because they have a good of their own. There is somebody there behind the fur or feathers. Our gaze is returned by an animal that itself has a concerned outlook. Here is value right before our eyes, right behind those eyes. Animals are value-able, able to value things in their world. But we may still want to say that value exists only where a subject has an object of interest. David Prall writes: 'The being liked or disliked of the object is its value . . . . Some sort of a subject is always requisite to there being value at all (Prall, 1921, p. 227). So at least the higher animals can value too, because they are experiencing subjects and can take an interest in things.

Do animals value anything intrinsically? We may not think that animals have the capacity, earlier claimed for humans, of conferring intrinsic value on anything else. Mostly they seek their own basic needs, food and shelter, and care for their young. But then why not say that an animal values its own life for what it is in itself, intrinsically, without further contributory reference? Else we have an animal world replete with instrumental values and devoid of intrinsic values, everything valuing the resources it needs, nothing valuing itself. That is implausible. Animals maintain a valued self-identity as they cope through the world. Valuing is intrinsic to animal life.

\section{Valuable Organisms}

Outdoors it is difficult to get out of sight of plants. It is also difficult for philosophers to 'see' plants philosophically. Few are botanists. Also, it is easy to overlook the insects. Even fewer philosophers are entomologists.

A plant is not a subject, but neither is it an inanimate object, like a stone. Plants, quite alive, are unified entities of the botanical though not of the zoological kind, that is, they are not unitary organisms highly integrated with centred neural control, but they are modular organisms, with a meristem that can repeatedly and indefinitely produce new vegetative modules, additional stem nodes and leaves when there is available space and resources, as well as new reproductive modules, fruits and seeds.

Plants make themselves; they repair injuries; they move water, nutrients, and photosynthate from cell to cell; they store sugars; they make tannin and other toxins and regulate their levels in defence against grazers; they make nectars and emit pheromones to influence the behaviour of pollinating insects and the responses 
Value in Nature and the Nature of Value

of other plants; they emit allelopathic agents to suppress invaders; they make thorns, trap insects. They can reject genetically incompatible grafts.

A plant, like any other organism, sentient or not, is a spontaneous, self-maintaining system, sustaining and reproducing itself, executing its program, making a way through the world, checking against performance by means of responsive capacities with which to measure success. Something more than physical causes, even when less than sentience, is operating; there is information superintending the causes; without it the organism would collapse into a sand heap. The information is used to preserve the plant identity.

All this cargo is carried by the DNA, essentially a linguistic molecule. The genetic set is really a prepositional set-to choose a provocative term-recalling how the Latin propositum is an assertion, a set task, a theme, a plan, a proposal, a project, as well as a cognitive statement. These molecules are set to drive the movement from genotypic potential to phenotypic expression. Given a chance, these molecules seek organic self-expression. An organism, unlike an inert rock, claims the environment as source and sink, from which to abstract energy and materials and into which to excrete them. It 'takes advantage' of its environment.

We pass to value when we recognize that the genetic set is a normative set; it distinguishes between what is and what ought to be. The organism is an axiological system, though not a moral system. So the tree grows, reproduces, repairs its wounds, and resists death. The physical state that the organism defends is a valued state. A life is defended for what it is in itself, without necessary further contributory reference. Every organism has a good-of-itskind; it defends its own kind as a good kind. In this sense, the genome is a set of conservation molecules.

Does not that mean that the plant is valuable (able to value) itself? If not, we will have to ask, as an open question: Well, the plant has a good of its own, but is there anything of value to it? ${ }^{1}$ Possibly, even though plants have a good of their own, they are not able to value because they are not able to feel anything. Nothing matters to a plant. Hence, says Peter Singer, 'there is nothing to be taken into account' (Singer, 1976, p. 154). There is plant good, but not plant value. There is no valuer evaluating anything. Plants can do things that interest us, but the plants are not interested in what they are doing. They do not have any options among which they are choosing. They have only their merely functional goods.

${ }^{1}$ Robin Attfield remarks that 'even if trees have needs and a good of their own, they may still have no value of their own' (Attfield, 1981, p. 35). 


\section{Holmes Rolston III}

But, though things do not matter to plants, things matter for them. We ask, of a failing plant: What's the matter with that plant? If it is lacking sunshine and soil nutrients, and we arrange for these, we say: The tree is benefiting from the sunshine and the soil nutrients; and benefit is - everywhere else we encounter it - a value word. Can we ask, as an open question: The tree is benefiting from the sun and the nutrients, but are those valuable to it? That hardly seems coherent. "This tree was injured when the elk rubbed its velvet off its antlers, and the tannin secreted there is killing the invading bacteria. But is this valuable to the tree?' Botanists say that the tree is irritable in the biological sense.

Or if trees cannot be irritated, you no doubt think that bees can, even though you may not know what to think about bees as subject valuers. Objectively, it is difficult to dissociate the idea of value from natural selection. Biologists regularly speak of the 'survival value' of plant activities: thorns have survival value. Bees sting and do their waggle dance. These survival traits, though picked out by natural selection, are innate (= intrinsic) in the organism, that is, stored in its genes and expressed in structure and behaviour.

But, it will be protested, careful philosophers will put this kind of 'value' in scare quotes. This is not really value at all, because there is no felt experience choosing from alternatives, no preferences being exercised. This so-called value is not a value, really, not one of interest to philosophers because it is not a value with interest in itself. Meanwhile we humans value many things about which we have no options (photosynthesis and protein), or even no knowledge (perhaps vitamin $B_{1}$ or the cytochrome-c molecules). What are we to say of all these functional 'values'? Do they become of real value only upon their discovery, and even then have only instrumental value?

Why is the organism not valuing what it is making resources of?-not consciously, but we do not want to presume that there is only conscious value or valuing. That is what we are debating, not assuming. A valuer is an entity able to defend value. Insentient organisms are the holders of value, although not the beholders of value. Some value is already present in nonsentient organisms, normative valuative systems, prior to the emergence of further dimensions of value with sentience. Otherwise we have to ask, as an open question: Well, the bee is making use of the nectar, but is the honey valuable to the bee? My mind is not subtle enough to use words with such precision. The bee's defending its own life for what it is in itself is just as much fact of the matter as is its using its stinger or making honey to do so.

No, these are observations of value in nature with just as much 
certainty as they are biological facts. We are misled to think that all the value of the tree, instrumental or intrinsic, must be subjectively conferred, like the greenness, a secondary quality, or even a tertiary one. A simpler, less anthropically based, more biocentric theory holds that some values, instrumental and intrinsic, are objectively there, discovered not generated by the valuer. Trees may not be coloured without a perceiver, but they exist per se; and only if their existence is dynamically defended. That is not an analogue of colour at all. Trees do appear to be green, and perhaps we do not want to call the electromagnetic waves actually there 'greenness'. Trees also photosynthesise with or without humans watching them. Even those who think that all the tree's intrinsic value has to be conferred by humans still think that matters can be better or worse for the tree, and this amounts to saying that the tree on its own has its goods and harms. Norton and Windelband, unable to forget their experiential omnipresence as valuers, have forgotten elementary biology.

Some worry that we here commit the naturalistic fallacy. We find what biologically is in nature and conclude that something valuable is there, something which we may say we ought to protect. But does it not rather seem that the facts here are value facts, when we are describing what benefits the tree? Such value is pretty much fact of the matter. If we refuse to recognize such values being objectively there, have we committed some fallacy? Rather, the danger is the other way round. We commit the subjectivist fallacy if we think all values lie in subjective experience, and, worse still, the anthropocentrist fallacy if we think all values lie in human options and preferences.

\section{Valuable Species}

On our travels we may see endangered species. If so, we will value them. But are we seeing, and valuing, species? Or just that trumpeter swan, this grizzly bear, that we were lucky enough to see? That is partly a scientific and partly a philosophical problem. I have seen, and valued, swans and bears in Yellowstone over four decades. But not the same individuals, rather bear replaced by bear replaced by bear, swan-swan-swan.

Certainly humans are able to value species both by instrumental use and by conferring intrinsic value on them. But can a species be value-able all by itself, able to value at the species-level? A species has no self. There is no analogue to the nervous hookups or circulatory flows that characterize the organism. But now we must ask 


\section{Holmes Rolston III}

whether singular somatic identity conserved is the only process that is valuable. A species is another level of biological identity reasserted genetically over time. Identity need not attach solely to the centred or modular organism; it can persist as a discrete pattern over time.

The life that the organismic individual has is something passing through the individual as much as something it intrinsically possesses. The genetic set, in which is coded the telos, is as evidently the property of the species as of the individual through which it passes. Value is something dynamic to the specific form of life. The species is a bigger event than the individual with its interests or sentience. Events can be good for the well-being of the species, considered collectively, although they are harmful if considered as distributed to individuals. When a wolf is tearing up an elk, the individual elk is in distress, but Cervus canadensis is in no distress. The species is being improved, shown by the fact that wolves will subsequently find elk harder to catch. If the predators are removed, and the carrying capacity is exceeded, wildlife managers may have to benefit a species by culling its member individuals.

Even the individuals that escape external demise die of old age; and their deaths, always to the disadvantage of individuals, are a necessity for the species. A finite life span makes room for those replacements that enable development, allowing the population to improve in fitness or to adapt to a shifting environment. The surplus of young, with most born to perish prematurely, is disadvantageous to such individuals, but advantageous to the species. Without the 'flawed' reproduction that incorporates mutation and permits variation, without selection of the more fit few, and death of the less fit, which harms most individuals, the species would soon be extinct in a changing environment. The individual is a receptacle of the form, and the receptacles are broken while the form survives, but the form cannot otherwise survive.

Reproduction is typically assumed to be a need of individuals, but since any particular individual can flourish somatically without reproducing at all, indeed may be put through duress and risk or spend much energy reproducing, by another logic we can interpret reproduction as the species staying in place by its replacements. In this sense a female grizzly does not bear cubs to be healthy herself. Rather, her cubs are Ursus arctos, threatened by nonbeing, recreating itself by continuous performance. A female animal does not have mammary glands nor a male testicles because the function of these is to preserve its own life; these organs are defending the line of life bigger than the somatic individual. The locus of the value that is defended over generations is as much in 
Value in Nature and the Nature of Value

the form of life, since the individuals are genetically impelled to sacrifice themselves in the interests of reproducing their kind.

An insistent individualist can claim that species-level phenomena (vitality in a population, danger to a species, reproduction of a life form, tracking a changing environment) are only epiphenomena, byproducts of aggregated individuals in their interrelationships. But our more comprehensive account, interpreting the species itself as a kind of individual, historic lineage over time, is just as plausible. Biologists have often and understandably focused on individual organisms, and some recent trends interpret biological processes from the perspective of genes. But a consideration of species reminds us that many events can be interpreted at this level too. Properly understood, the story at the microscopic genetic level reflects the story at the ecosystemic specific level, with the individual a macroscopic mid-level between. The genome is a kind of map coding the species; the individual is an instance incarnating it.

Much of what we earlier said about individual organisms as nonmoral normative systems can be resaid, mutatis mutandis, of species. The single, organismic-directed course is part of a bigger picture in which a species too runs a telic course through the environment, using individuals resourcefully to maintain its course over much longer periods of time. The species line is the vital living system, the whole, of which individual organisms are the essential parts. The species defends a particular form of life, pursuing a pathway through the world, resisting death (extinction), by regeneration maintaining a normative identity over time. It is as logical to say that the individual is the species' way of propagating itself as to say that the embryo or egg is the individual's way of propagating itself. The value resides in the dynamic form; the individual inherits this, exemplifies it, and passes it on. If so, what prevents value existing at that level? The appropriate survival unit is the appropriate location of valuing.

Even a species is a kind of valuer. Species as historical lines have a defended biological identity, though they do not have any subjective experience. Species are quite real; that there really is a bear-bear-bear sequence is about as certain as anything we believe about the empirical world. Species are lively and full of life, they are processes, they are wholes, they have a kind of unity and integrity. The species line too is value-able, able to conserve a biological identity. Indeed it is more real, more value-able than the individual, necessary though individuals are for the continuance of this lineage.

We said earlier that natural selection picks out whatever traits an organism has that are valuable to it, relative to its survival. But if 


\section{Holmes Rolston III}

we ask what is the essence of this value, it is not the somatic survival of the organismic individual; this value ability is the ability to reproduce. That locates value-ability innate or intrinsic within the organism, but it just as much locates the value-ability as the capacity to re-produce a next generation, and a next generation positioned to produce a next generation after that. Any biocentrism that focuses on individuals has got to argue away the fact that natural selection is rather careless with individuals; the test to which it puts them is whether they can pass on the historical lineage.

\section{Valuable Ecosystems}

Exploring, we will see different ecosystems: an oak-hickory forest, a tall grass prairie. At least we see trees and grasses. But do we see ecosystems? Maybe we immerse ourselves in them, for an ecosystem is not so much an object in the focus of vision as an enveloping community, a place in space, a process in time, a set of vital relationships. This can mean that philosophers have difficulty seeing, and valuing, ecosystems. Yet, really, the ecosystem is the fundamental unit of development and survival.

Humans can value whatever they wish in nature. This can include ecosystems. 'A thing is right,' concluded Aldo Leopold, 'when it tends to preserve the integrity, stability, and beauty of the biotic community. It is wrong when it tends otherwise' (Leopold, 1966, p. 240). Leopold wanted a 'land ethic'. So humans can value ecosystem communities intrinsically - for what they are in themselves-as well as instrumentally. But can ecosystems be valuable all by themselves?

Actually, there is a deeper worry again, partly scientific and partly philosophical. Perhaps ecosystems do not exist-or exist in too loose a way to be valuers. They are nothing but aggregations of their more real members, like a forest is (some say) nothing more than a collection of trees. Even a human will have trouble valuing what does not really exist. We can value collections, as of stamps, but this is just the aggregated value of individual stamps. Still, an ecosystem, if it exists, is rather different. Nothing in the stamp collection is alive; the collection is neither self-generating nor selfmaintaining. Neither stamp nor collection is valuable on its own. But perhaps ecosystems are both valuable to humans and, if they exist, value-able as systems in themselves.

We need ecology to discover what biotic community means as an organisational mode. Then we can reflect philosophically to discover the values there. Ecosystems can seem little more than sto- 


\section{Value in Nature and the Nature of Value}

chastic processes. A sea-shore, a tundra, is a loose collection of externally related parts. Much of the environment is not organic at all (rain, groundwater, rocks, nonbiotic soil particles, air). Some is dead and decaying debris (fallen trees, scat, humus). These things have no organized needs; the collection of them is a jumble. The fortuitous interplay between organisms is simply a matter of the distribution and abundance of organisms, how they get dispersed, birth rates and death rates, population densities, moisture regimes, parasitism and predation, checks and balances. There is really not enough centred process to call community.

An ecosystem has no brain, no genome, no skin, no self-identification, no telos, no unified program. It does not defend itself against injury or death. It is not irritable. The parts (foxes, sedges) are more complex than the wholes (forests, grasslands). So it can begin to seem as if an ecosystem is too low a level of organisation to be the direct focus of concern. Ecosystems do not and cannot care; they have no interests about which they or we can care.

But this is to misunderstand ecosystems, to make a category mistake. To fault communities as though they ought to be organismic individuals is to look at one level for what is appropriate at another. One should look for a matrix of interconnections between centres, for creative stimulus and open-ended potential. Everything will be connected to many other things, sometimes by obligate associations, more often by partial and pliable dependencies; and, among other components, there will be no significant interactions. There will be shunts and criss-crossing pathways, cybernetic subsystems and feedback loops. One looks for selection pressures and adaptive fit, not for irritability or repair of injury, for speciation and life support, not for resisting death. We must think more systemically, and less organismically.

An ecosystem generates a spontaneous order that envelops and produces the richness, beauty, integrity and dynamic stability of the component parts. Though these organized interdependences are loose in comparison with the tight connections within an organism, all these metabolisms are as vitally linked as are liver and heart. The equilibrating ecosystem is not merely push-pull forces. It is an equilibrating of values.

We do not want in an undiscriminating way to extrapolate criteria of value from organism to biotic community, any more than from person to animal or from animal to plant. Rather, we want to discriminate the criteria appropriate to this level. The selective forces in ecosystems at once transcend and produce the lives of individual plants and animals. Evolutionary ecosystems over geological time have increased the numbers of species on Earth from 


\section{Holmes Rolston III}

zero to five million or more. R. H. Whittaker found that on continental scales and for most groups 'increase of species diversity ... is a self-augmenting evolutionary process without any evident limit'. There is a tendency toward what he called 'species packing' (Whittaker, 1972, p. 214).

Superimposed on this, the quality of individual lives in the upper trophic rungs of ecological pyramids has risen. One-celled organisms evolved into many-celled, highly integrated organisms. Photosynthesis evolved and came to support locomotion-swimming, walking, running, flight. Stimulus-response mechanisms became complex instructive acts. Warm-blooded animals followed cold-blooded ones. Neural complexity, conditioned behaviour, and learning emerged. Sentience appeared-sight, smell, hearing, taste, pleasure, pain. Brains evolved, coupled with hands. Consciousness and self-consciousness arose. Persons appeared with intense concentrated unity. The products are valuable, able to be valued by these humans; but why not say that the process is what is really value-able, able to produce these values?

Ecosystems are selective systems, as surely as organisms are selective systems. The system selects over the long ranges for individuality, for diversity, for adapted fitness, for quantity and quality of life. Organisms defend only their own selves or kinds, but the system spins a bigger story. Organisms defend their continuing survival; ecosystems promote new arrivals. Species increase their kinds, but ecosystems increase kinds, and increase the integration of kinds. The system is a kind of field with characteristics as vital for life as any property contained within particular organisms. The ecosystem is the depth source of individual and species alike.

In the current debate among biologists about the levels at which selection takes place-individual organisms, populations, species, genes - the recent tendency to move selective pressures down to the genetic level forgets that a gene is always emplaced in an organism that is emplaced in an ecosystem. The molecular configurations of DNA are what they are because they record the story of a particular form of life in the macroscopic, historical ecosystem. What is generated arises from molecular mutations, but what survives is selected for adaptive fit in an ecosystem. We cannot make sense of biomolecular life without understanding ecosystemic life, the one level as vital as the other.

Philosophers, sometimes encouraged by biologists, may think ecosystems are just epiphenomenal aggregations. This is a confusion. Any level is real if there is significant downward causation. Thus the atom is real because that pattern shapes the behaviour of electrons; the cell because that pattern shapes the behaviour of 
amino acids; the organism because that pattern co-ordinates the behaviour of hearts and lungs; the community because the niche shapes the morphology and behaviour of the foxes within it. Being real requires an organisation that shapes the existence and the behaviour of members or parts.

Axiologically, in the more comprehensive levels, the terms 'instrumental' and 'intrinsic' do not work very well. Ecosystems have 'systemic value'. But if we want to know what is value-able, able to create value, why not say that it is the productivity of such ecosystems, bringing into existence these phenomena that, when we arrive, the human consciousness is also able to value? What is incredible is not the existence of ecosystems. What is really incredible is that we humans, arriving late on the evolutionary scene, ourselves products of it, bring all the value into the world, when and as we turn our attention to our sources. That claim has too much subjective bias. It values a late product of the system, psychological life, and subordinates everything else to this. It mistakes a fruit for the whole plant, the last chapter for the whole story.

All value does not end in either human or non-human intrinsic value, to which everything else is contributory. Values are intrinsic, instrumental, and systemic, and all three are interwoven, no one with priority over the others in significance, although systemic value is foundational. Each locus of intrinsic value gets folded into instrumental value by the system, and vice versa. There are no intrinsic values, nor instrumental ones either, without the encompassing systemic creativity. It would be foolish to value the golden eggs and disvalue the goose that lays them. It would be a mistake to value the goose only instrumentally. A goose that lays golden eggs is systemically valuable. How much more so is an ecosystem that generates myriads of species, or even, as we next see, an Earth that produces billions of species, ourselves included.

\section{Valuable Earth}

I promised to explore the whole world; so let's get the planet in focus. Viewing Earthrise, Edgar Mitchell, was entranced: "Suddenly from behind the rim of the moon, in long-slow motion moments of immense majesty, there emerges a sparkling blue and white jewel, a light, delicate sky-blue sphere laced with slowly swirling veils of white, rising gradually like a small pearl in a thick sea of black mystery. It takes more than a moment to fully realize this is Earth . . . home' (Kelley, 1988, at photographs 42-45). Michael Collins was Earthstruck: 'When I travelled to the moon, it 
wasn't my proximity to that battered rockpile I remember so vividly, but rather what I saw when I looked back at my fragile home - a glistening, inviting beacon, delicate blue and white, a tiny outpost suspended in the black infinity. Earth is to be treasured and nurtured, something precious that must endure' (Gallant, 1980, p. 6).

Pearls are, a philosopher might object, valuable only when humans come around. But this mysterious Earth-pearl, a biologist will reply, is a home long before we humans come. This is the only biosphere, the only planet with an ecology. Earth may not be the only planet where anything, is valuable-able to be valued by humans intrinsically or instrumentally-but it is the only place able to produce vitality before humans come. The view from space symbolizes all this.

Earlier the challenge was to evaluate persons, animals, plants, species, ecosystems; but environmental valuing is not over until we have risen to the planetary level. Earth is really the relevant survival unit. But valuing the whole Earth is unfamiliar and needs philosophical analysis. We may seem to be going to extremes. Earth is, after all, just earth. The belief that dirt could have intrinsic value is sometimes taken as a reductio ad absurdum in environmental philosophy. Dirt is not the sort of thing that has value by itself. Put like that, we agree. An isolated clod defends no intrinsic value and it is difficult to say that it has much value in itself. But that is not the end of the matter, because a clod of dirt is integrated into an ecosystem; earth is a part, Earth the whole. Dirt is product and process in a systemic nature. We should try to get the global picture, and switch from a lump of dirt to the Earth system in which it has been created.

Earth is, some will insist, a big rockpile like the moon, only one on which the rocks are watered and illuminated in such way that they support life. So maybe it is really the life we value and not the Earth, except as instrumental to life. We do not have duties to rocks, air, ocean, dirt, or Earth; we have duties to people, or living things. We must not confuse duties to the home with duties to the inhabitants. We do not praise so much the dirt as what is in the dirt, not earth so much as what is on Earth. But this is not a systemic view of what is going on. We need some systematic account of the valuable Earth we now behold, before we beheld it, not just some value that is generated in the eye of the beholder. Finding that value will generate a global sense of obligation.

The evolution of rocks into dirt into fauna and flora is one of the great surprises of natural history, one of the rarest events in the astronomical universe. Earth is all dirt, we humans too arise up 
Value in Nature and the Nature of Value

from the humus, and we find revealed what dirt can do when it is self-organizing under suitable conditions. This is pretty spectacular dirt. Really, the story is little short of a series of 'miracles', wondrous, fortuitous events, unfolding of potential; and when Earth's most complex product, Homo sapiens, becomes intelligent enough to reflect over this cosmic wonderland, everyone is left stuttering about the mixtures of accident and necessity out of which we have evolved. For some the black mystery will be numinous and signal transcendence; for some the mystery may be impenetrable. Perhaps we do not have to have all the cosmological answers. Nobody has much doubt that this is a precious place, a pearl in a sea of black mystery.

The elemental chemicals of life-carbon, oxygen, hydrogen, nitrogen-are common enough throughout the universe. They are made in the stars. But life, rare elsewhere, is common on Earth, and the explanation lies in the ordinary elements in an extraordinary setting, the super-special circumstances in which these common chemicals find themselves arranged on Earth, that is, in the self-organizing system. On an everyday scale, earth, dirt, seems to be passive, inert, an unsuitable object of moral concern. But on a global scale?

The scale changes nothing, a critic may protest, the changes are only quantitative. Earth is no doubt precious as life support, but it is not precious in itself. There is nobody there in a planet. There is not even the objective vitality of an organism, or the genetic transmission of a species line. Earth is not even an ecosystem, strictly speaking; it is a loose collection of myriads of ecosystems. So we must be talking loosely, perhaps poetically or romantically, of valuing Earth. Earth is a mere thing, a big thing, a special thing for those who happen to live on it, but still a thing, and not appropriate as an object of intrinsic or systemic valuation. We can, if we insist on being anthropocentrists, say that it is all valueless except as our human resource.

But we will not be valuing Earth objectively until we appreciate this marvellous natural history. This really is a superb planet, the most valuable entity of all, because it is the entity able to produce all the Earthbound values. At this scale of vision, if we ask what is principally to be valued, the value of life arising as a creative process on Earth seems a better description and a more comprehensive category.

Perhaps you think that species are unreal. Perhaps you still insist that ecosystems are unreal, only aggregations, but how about Earth? Will you say that Earth too, being a higher level entity, is unreal? Only an aggregation, and not a systemic whole? There is 


\section{Holmes Rolston III}

no such thing as a biosphere? Surely, Earth has some rather clear boundaries, does it not? Will you say that this is a planet where nothing matters? Nothing matters to Earth, perhaps, but everything matters on Earth, for Earth.

Do not humans sometimes value Earth's life-supporting systems because they are valuable, and not always the other way round? Is this value just a matter of late-coming human interests? Or is Earth not historically a remarkable, valuable place, a place able to produce value prior to the human arrival, and even now valuable antecedently to the human uses of it? It seems parochial to say that our part alone in the drama establishes all its worth, The production of value over the millenia of natural history is not something subjective that goes on in the human mind. In that sense, a valuable Earth is not the reductio ad absurdum of valuing dirt. It is not even locating the most valuable thing in the world; it is locating the ultimate value of the world itself. The creativity within the natural system we inherit, and the values this generates, are the ground of our being, not just the ground under our feet. Earth could be the ultimate object of duty, short of God, if God exists.

\section{Valuable Nature}

William James, toward the beginning of our century, starkly portrayed the utterly valueless world, transfigured as a gift of the human coming:

Conceive yourself, if possible, suddenly stripped of all the emotion with which your world now inspires you, and try to imagine it as it exists, purely by itself, without your favorable or unfavorable, hopeful or apprehensive comment. It will be almost impossible for you to realize such a condition of negativity and deadness. No one portion of the universe would then have importance beyond another; and the whole collection of its things and series of its events would be without significance, character, expression, or perspective. Whatever of value, interest, or meaning our respective worlds may appear endued with are thus pure gifts of the spectator's mind. (James, 1925, p. 150)

At the end of this century, this is not what the astronauts think at all. They do not see Earth as negativity and deadness, nor do they think that this portion of the universe has no significance beyond any other part, except by gift of our spectating minds. They did not say that the world was valuable only because they took along an indubitable self into space and projected value onto Earth. 
Value in Nature and the Nature of Value

They rather see that human life arises in a spectacular place, in a nature of whose creative patterns they are part.

According to the old paradigm, so long dominant that to some it now seems elementary, there is no value without an experiencing valuer, just as there are no thoughts without a thinker, no percepts without a perceiver, no deeds without a doer, no targets without an aimer. Valuing is felt preferring by human choosers. Possibly, extending this paradigm, sentient animals may also value. But plants cannot value; they have no options and make no choices. $A$ fortiori, Earth and nature cannot be bona fide valuers. One can always hang on to the claim that value, like a tickle or remorse, must be felt to be there. Its esse is percipi. Nonsensed value is nonsense. It is only beings with 'insides' to them that have value.

But the problem with the 'no value without a valuer' axiom is that it is too individualistic; it looks for some centre of value located in a subjective self. And we nowhere wish to deny that such valuers are sufficient for value. But that is not the whole account of value in a more holistic, systemic, ecological, global account. Perhaps there can be no doing science without a scientist, no religion without a believer, no tickle without somebody tickled. But there can be law without a lawgiver, history without a historian; there is biology without biologists, physics without physicists, creativity without creators, story without story-tellers, achievement without achievers-and value without valuers. A sentient valuer is not necessary for value. Another way is for there to be a value-generating system able to generate value. If you like, that is another meaning of value-er; any $x$ is a valuer if $x$ is value-able, able to produce values.

It is true that humans are the only evaluators who can reflect about what is going on at this global scale, who can deliberate about what they ought to do conserving it. When humans do this, they must set up the scales; and humans are the measurers of things. Animals, organisms, species, ecosystems, Earth, cannot teach us how to do this evaluating. But they can display what it is that is to be valued. The axiological scales we construct do not constitute the value, any more than the scientific scales we erect create what we thereby measure.

Humans are not so much lighting up value in a merely potentially valuable world, as they are psychologically joining ongoing planetary natural history in which there is value wherever there is positive creativity. While such creativity can be present in subjects with their interests and preferences, it can also be present objectively in living organisms with their lives defended, and in species that defend an identity over time, and in systems that are self- 


\section{Holmes Rolston III}

organizing and that project storied achievements. The valuing subject in an otherwise valueless world is an insufficient premise for the experienced conclusions of those who value natural history. Conversion to a biological and geological view seems truer to world experience and more logically compelling. This too is a perspective, but ecologically better informed; we know our place on a home planet. From this more objective viewpoint, there is something subjective, something philosophically naive, and even something hazardous in a time of ecological crisis, about living in a reference frame where one species takes itself as absolute and values everything else in nature relative to its potential to produce value for itself. Such philosophers live in an unexamined world, and, in result, they and those they guide live unworthy lives, because they cannot see their valuable world. 


\section{References}

Attfield, Robin 1981. 'The Good of Trees', Journal of Value Inquiry 15, 35-54.

Callicott, J. Baird 1984. 'Nonanthropocentric Value Theory and Environmental Ethics', American Philosophical Quarterly 21, 299-309.

Callicott, J. Baird 1986. 'On the Intrinsic Value of Nonhuman Species', in B. Norton, ed,. The Preservation of Species. Princeton: Princeton University Press.

Gallant, Roy A. 1980, Our Universe. Washington, DC: National Geographic Society.

James, William 1925. Varieties of Religious Experience. New York: Longman's, Green.

Kelley, Kevin W. (ed) 1988. The Home Planet. Reading, MA: Addison-Wesley.

Leopold, Aldo 1967. A Sand County Almanac New York: Oxford University Press.

Norton, Bryan G. 1991. Toward Unity Among Environmentalists. New York: Oxford University Press.

Prall, David 1921. A Study in the Theory of Value. Berkeley, CA: University of California Press.

Singer, Peter 1976, 'A11 Animals Are Equal', in Tom Regan and Peter Singer (eds.), Animal Rights and Human Obligations. Englewood Cliffs, NJ: Prentice-Hall.

Whittaker, R. H. 1972. 'Evolution and Measurement of Species Diversity', Taxon 21, 213-251.

Windelband, Wilhelm 1921. An Introduction to Philosophy. London: T. Fisher Unwin. 